\title{
COVID 19 Pandemic and Health Care Services: An Emergency Best Managed by Medical and Nursing Health Professionals; Together, Keeping Hand in Hand
}

\author{
Dr. Tanay Maiti ${ }^{1}$ Dr. Suwersh Narula-Khanna ${ }^{2}$ \\ ${ }^{1}$ Psychiatrist, AIIMS Bhubaneswar Odisha, India \\ ${ }^{2}$ Retired Professor Emeritus, Nursing 137, Thornwood Road, Stamford, Connecticut,USA. \\ Corresponding email: drtanaymaiti@gmail.com, drsuwersh@gmail.com
}

Modern health care is a perfect example of complete team work with multiple stake holders of various professional origin and expertise; whose dedication, commitment and sense of responsibility has resisted the current pandemic so well; facing endless challenges with the limited resources they have.

Needless to say, this mammoth task would not have fulfilled without the proper integration of all these services, including both the nursing and medical care, which has remained the basic pillars for the entire system. This synchronous work with mutual understanding about the other's work and timely needs have smoothened the health care functioning which has been reflected for multiple times in the past, specially during the time of any health emergency; and the current COVID 19 pandemic has re experienced this over the entire globe. Like all other beautifully integrated team works, the health care system too has resisted this major threat to mankind with much expertise and confidence than what it could have turned for an individual based approach.

Keyword: Covid-19, Health care services, medical \& Health care professional, emergency management.

Pattern of work: why a team is needed:

The word team has been used in different purpose at different context. As per Merriam Webster the word team can be defined as 'a number of persons associated together in work or activity'. (https://www.merriamwebster.com/dictionary/team)

Many of the modern public services are more than mere single handed or individual approach where multiple expertise is needed simultaneously to provide the best possible service. Health care services, which can be best expressed as a complex cognitively oriented, evidence and literature supported, skill based task where every step starting from the decision making to waste management all are much interrelated which should work smoothly, supported independently yet simultaneously. The failure at one part significantly affects the whole system, jeopardising the service provision which could turn life threating for many because of its typical nature of service and people who avail the service. For example, the often unnoticed cleaning and maintenance staffs are much pivotal for entire health care service without whose efficient and

51 GFNPSS International Journal of Multidisciplinary Research, Volume 1, Issue 2, July 2020 
tirelessly executed job, the whole system would have faced massive difficulty, increasing the chance of hospital borne infection putting health risk for not only the patients but also for the entire staffs. A comprehensive review by Oandanson et al. reviewed all the team work related literature over a span of nearly 20 years(1985 to 2004) and concluded about better organizational effectiveness and improved patient care when more diverse clinical expertise are involved in team decision making. (Oandanson 2006)

In a time, when scientific and technological advances are bringing up new forms of treatment in the previously declared 'so-called untreatable' diseases or disorders, it is not practically possible for any single individual to learn all and apply the same simultaneously. Medical sciences and health care services are more than just clinical knowledge and skills by now, where being technologically sound and updated has turned among the primary requisites for the any health professionals today. Also, health care sector takes important part for national economic policy in most of the developed countries; and in the developing or LAMIC ones, though the health care budget shares a very limited part of the national budget, but it remains under constant and strict scrutiny, and a comprehensive delivery is often expected by the population even with the limited resources (Micheal A. 2000).

Hence, to make best use of recent advances in compromised settings where judicious resource management with minimal wastage is very important where appropriate team work can turn very pivotal and absolutely essential too.

Integration is the key: Sulivanet al. described four basic elements needed for a better and collaborative team work at health care sector which are; co ordination, co operation, shared decision making and partnerships. (Sullivan, T. J. 1998).A perfectly integrated team work at hospital settings can benefit the outcome both quantitatively and qualitatively. Reducing the duration of hospital stay, improved compliance to the prescribed medications, better audit results (Reeves 2011)and covering the psychosocial issues (Elsayem, A, 2004) are clear quantitative benefits where qualitative parameters like better evidence based practice (Reeves 2011)improved decision making (Propp 2010)with increased innovation as well. (Pike 1993)

All the recent advances and newer techniques can be best used only if they are being implemented accordingly, and learnt by many professionals together over any single self. The massive patient load, the 
nature and level of complications along with restricted resources in most of the countries and health settings definitely needs a majorly integrated team work, failing which all individual effort might go in vain.

COVID 19 and Indian battle: India documented its very first case on $30^{\text {th }}$ January 2020 with first death on $10^{\text {th }}$ of March from the state of Karnataka for a 76 years old individual. Since then the graph of infected ones, associated morbidity hospital admissions and fatal outcomes have increased only all over the country. Various states in India have shown different infection rates and varied responses to it; however states like Kerala, Maharashtra Delhi have seen massive rates of infection with high mortality rate, though their battle with the illness, with the collaboration of all the health staffs have controlled the situation much satisfactorily. Over this few months, India has witnessed major changes in health care sector including its decision making, service providing reserve plans and safety measures for the workers in the system. All the health workers have accustomed to this 'new normal' very fast and both the nursing and medical staff also has taken massive role in the teaching educating and training the other staffs including the junior ones from their own fraternity. Other than direct in person events, the tele mode has played a huge and important role during this pandemic with proper use of technologies. Social medias, till now mostly used as promotional and recreational platform; played a completely different role of mass education and awareness where the health care workers contributed immensely too. Though rumors, fake or propaganda based news diluted this effect, but after the initial jitteriness and clouding of information at the social media platforms; these health awareness messages, videos educative talks and interactive sessions alleviated much of anxiety in general population; and also helped them to keep the faith intact on their skill and expertise.

Nature of collaboration during covid-19 time: It was a famous proverb that Nursing and medicine go hand in hand from its inception. The nature of collaboration in reality was like boss and hand maiden, paramedical and subservient in nature. After centuries of this kind of pattern in existence; suddenly Covid-19 has changed the need from subservient and paramedical nature to real time collaboration on equal footing if not more for nurses. It has been realized by some legend leaders from both professions that there is a need of strong collaboration in order to care for the patients and to care for the caregiver (doctor and nurse). 
The wonderful example of collaboration during Covid-19 Pandemic is seen in these world organizations which are WHO, UNICEF and WFO (World Food Program).

These have accelerated collaborative efforts to find vaccine and effective treatments for all who need them for prevention and cure. The strategic preparedness and response plan aims to:

1. Coordinate across regions to assess, respond and mitigate risks

2. Improve country preparedness and response

3. Accelerate research and development

The steps taken include:

1. Buying and shipping PPE to 133 countries

2. Addressing market shortage by establishing PPE Consortium, Diagnostics Consortium and clinical Care Consortium

3. Providing information to the public by taking steps to protect yourself \& mythbusters, guidance to school \& workplace, guidance to health workers \& parents, guidance on mass gatherings and safe Ramadan practices

4. Strengthening the Laboratory capacity by supplying 1.5 million diagnostic kits to 126 countries
5. Building capacity to respond by developing multilingual online courses, making platforms available to Covid-19 partners, and by providing Emergency Medical Teams which are working in coordinated response operation

6. Solidarity trials to find vaccines and treatment.

This example of collaborative efforts lead the way for doctors and nurses to collaborate and unify as a team to battle against Covid-19 Pandemic. In words of Ingrid M. Nembhard\& et.al; "Effective team work hinges on accurate, frequent, timely, and problem-solving communications bolstered by shared goals, shared knowledge, and mutual respect-requirements collectively called relational coordination" (UN Foundation.org )

The Medicine \& Nursing should team up to work under VUCA (volatile, Uncertain, complex, and ambiguous situation) condition. The team work can be achieved through shared meetings \& protocols, tiered huddles, identification of boundary spanners, and shared conflict resolution strategies. The conducive environment (freely asking questions, raising concerns, sharing differences of opinion about strategy) "fosters quality and safety outcomes and bridges differences effectively, fostering learning and 
innovation" says Ingrid M. Nembhard\& et. al.

Sacrifices: The very professional need and nature of any health care professionals are quite time consuming, with working non stop even at odd hours definitely putting aside their other personal and recreational preferences or wishes. Both the personal and family lives of these individuals are highly compromised though the acceptance of the same has made it quite a 'norm' like other emergency service providers for example, police or fire brigade professionals. Along with this, the current situation is constantly witnessing loss of health often up to a much serious level causing loss of lives of these professionals. While nearly 22,000 people got infected by COVID 19 across more than 50 countries by April 2020 which turned nearly 90000 in number and the number is still rising without seeing any halt in the number.

(health.economictimes.indiatimes.com)

In India, till now, we have lost many of these front line warriors, both the medical and nursing professionals who collapsed after getting infected while providing their tireless humanitarian services. By first week of May 2020, more than 500 doctors nurses and paramedics got infected in India including significant deaths of some prominent ones. (www.hindustantimes.com/india-

news) up to the end of May 2020, prominent print media reported about more than thirty documented death of health care providers around the India, and some of the incidents even faced major difficulty at their cremations or last rites.

Mental health concerns: Though we forget it often, care providers are no super humans and needs some care too, to say the least. The sudden load and huge burden of illnesses, that also out of a very novel causative agent along with its unforeseen course and complications have constantly puzzled the world governing bodies for health, so the situation and condition of any individual health care provider can be imagined easily. As the pandemic has progressed and has extended like a light wave across the globe and work load and stress of the same has increased proportionally. Many of the health care providers, both the medical and nursing professionals are giving continuous hours of services with minimal or nil rests in between (Cai H., 2020). Use of the safety measures like Personal Protective Equipment or PPEs are even more cumbersome to use properly given the long hours of wearing it in a hot and humid climate. The fear of getting self infected or further infecting the family members or the near ones have often 
generated the sense of panic or acute bouts of anxiety which is quite easily understandable. The other reasons, as observed during previously witnessed similar health emergencies could be use of inadequate PPEs, over enthusiastic media coverage or feeling of being inadequately supported by the authorities. (Tam C.W.C et al, 2004, Lee S.M., 2018, Styra R., 2008). In the background of current pandemic, Kang et al did a cross sectional study from Wuhan itself( $(n=994)$ where they found nearly $40 \%$ having subthreshold mental health disturbances, where upto $23 \%$ and $7 \%$ have moderate and severe disturbances (Kang L.,2020). Cai et al also found many medical staffs have experienced major emotional stress during this COVID 19 outbreak. (Cai H., 2020)

Clinically significant depressive symptoms were found among many of the doctors and nurses by other researchers (Liang Year., 2020). Depression anxiety insomnia and distress have remained the prominent complains from many of this service providers (Lai J., 2020).

In this background, needless to say that working in a team definitely lessens one's individual sense of burden, also the bonding care and distress sharing one can avail in a team can make everyone's job easy.

Health suggestions: As you know that a deliberate suggestion can influence how well people remember things, how they respond to medical treatments, and even how well they will perform and behave. Once you expect something to happen, your behavior, thoughts, and reactions will actually contribute to making that expectation occur. Using suggestion in this way can be a powerful tool in accomplishing our goals. There are four ways to use the power of suggestion are:

1. Turn into the moment

2. Create a network of support

3. Maintain a flexible mindset

4. Understand that the power of suggestion is always working

There are many suggestions for the health workers especially nurses and doctors who are working in the frontline should follow in order to avoid emotional eating due to Coronavirus stress:

Cynthia Sass, a registered dietitian shares her five-step strategy for avoiding emotional eating, even during the Covid-19 pandemic:

1. Tune into your body's cues

2. Connect the dots between feelings and food

3. Create an eating schedule (Easier said than done if on duty)

4. Eat without distractions

5. Be kind to yourself

The health workers should balance between their nutrition, exercise, mental health and 
self-care (sleep, hygiene). There should be safety at work place. Tips for good healthy life includes: Have heavy breakfast, drink 8 glasses of water daily, include 5 food groups in your diet, positive thinking, enjoy chatting with your friend, workout 5 days per week, asleep 7-8 hours daily and add to do list before bedtime.

Carole Jackus suggests 21 ways to keep yourself healthy

(21 Ways Nurses can stay healthy and Happy/working Nurse>articles>21-ways)

1. Set realistic goal

2. Create an exercise plan

3. Find a place to exercise near your residence

4. Be flexible

5. keep open mind

6. Improve your nutrition

7. Eat healthy breakfast

8. Bring nutritious lunch to work

9. Choose healthy snacks

10. Incorporate Omega-3

11. Get plenty of Calcium and Vitamin D

12. Practice portion control for optimum nutrition

13. Monthly Breast Exam or testicular exam

14. Weigh yourself weekly

15. Quit smoking if you are a smoker

16. Drink alcohol in moderation

17. Maintain emotional health
18. Boost your confidence by practicing your skills

19. Follow your dreams

20. Cultivate healthy relationships

21. Do your leisure activities

The healthy status is important to be maintained by the health workers, so that they can assist the patient at optimum level of quality care. In Covid-19 Pandemic, it has become more imperative that nurses and doctors should not work more than four hours in one shift. It's horrible and equally painful to go on in PPE for 8 hour shift without water, eating or urinating. The frontline health workers are having their immune system going down, sleep deprivation, dehydration, headaches, dizziness, confusion in the mind, problems of diaper wearing, monthly periods problem in the female workers, skin bruises, unable to see properly through misty eye shields etc. are adding to unhealthy status of the nurses and doctor who are becoming more vulnerable to get infections of Covid-19.

Conclusion: Health care have always remained a complicated and multi-winged matter, where teamwork is pivotal. Both the medicinal and surgical interventions had always needed multiple persons for different stages of the treatment. For special and emergency challenges like current COVID 19 one probably needs more of team work, 
as the situation is novel and so are the work related hindrances and obstacles. The constant research of various labs and pharmaceutical giants are bringing up many new hopes for the intervention of COVID 19 situations, but for the successful implementation of the same a perfect team work with solid blend of medical and nursing expertise can improve the situation further, restoring the faith and superiority of both science and human efforts, over this deadly virus.

\section{References:}

I. Cai H., Tu B., Ma J., Chen L., Fu L., Jiang Y., Zhuang Q. Psychological impact and coping strategies of frontline medical staff in Hunan between January and March 2020 during the outbreak of coronavirus disease 2019 (COVID19) in Hubei, China. Med. Sci. Monit. 2020;26

II. Elsayem, A., Swint, K., \&Fisch, M. J., et al. (2004). Palliative care inpatient service in a comprehensive cancer center: clinical and financial out- comes. J ClinOncol 22(10), 2008-2014.

III. Kang L., Li Y., Hu S., Chen M., Yang C., Yang B.X. The mental health of medical workers in Wuhan, China dealing with the 2019 novel coronavirus. Lancet
Psychiatry. 2020;7:e14.[PMC free article] [PubMed] [Google

$\underline{\text { Scholar}}$ [Ref list]

IV. Lai J., Ma S., Wang Y., Cai Z., Hu J., Wei N. Factors associated with mental health outcomes among health care workers exposed to coronavirus disease 2019. JAMA network open. 2020;3[PMCfreearticle] [PubM ed] [ Google Scholar] [Ref list]

V. Lee S.M., Kang W.S., Cho A., Kim T., Park J.K. Psychological impact of the 2015 MERS outbreak on hospital workers and quarantined hemodialysis patients. Compr. Psychiatry. 2018;87:123-127. [PMC freearticle] [PubMed] [GoogleScholar ][Ref list]

VI. Liang Y., Chen M., Zheng X., Liu J. Screening for Chinese medical staff mental health by SDS and SAS during the outbreak of COVID-19. J. Psychosom. Res. 2020;133:11011102. [PMCfreearticle] [PubMed] [ $\underline{\text { Go }}$ $\underline{\text { ogle Scholar] [Ref list] }}$

VII. Micheal A. West. Team working and effectiveness in health care British Journal of Health Care Management . August 2000

VIII. Nembhard, I. M., Lee, Y. S. H. et al. A quasi-experiment assessingthe six months effects of a Nurse coordination program on patient care 
experiences and clinician teamwork in Community health centers. BMC Health Serv Res 20, 137 (2020). https://doi.org/10.1186/s12913-0204986-0

IX. Health suggestions nursing and medicine/16Medical tips that Doctors and Nurses Wish you knew/The Healthy

X. Oandasan, Ivy \& Baker, G. \& Barker, Keegan \& Bosco, Carmela \& D'amour, Danielle \& Jones, Linda \&Bsn, Rn \&Kimpton, Shandra\&sc, M. \& Lemieux-Charles, Louise \&Nasmith, Louise \& San MartinRodriguez, Leticia. (2006). Teamwork in Healthcare: Promoting Effective Teamwork in Healthcare in Canada. Canadian Health Services Research Foundation

XI. Pike, A. W., McHug, M., Canney, K. C., Miller, N. E., Reiley, P., \& Seibert, C. (1993). A new architecture for quality assurance: nursephysician collaboration. J Nurs Care Qual 7(3), 1-8.

XII. Propp, K. M., Apker, J., Zabava Ford, W. S., Wallace, N., Serbenski, M., \&Hofmeister, N. (2010). Meeting the complex needs of the health care team: identification of nurse-team communication practices perceived to enhance patient outcomes. Qual Health Res 20(1), 15-28.

XIII. Reeves, S., Lewin, S., Espin, S., \&Zwarenstein, M. (2011)Interprofessional teamwork for health and social care 8. John Wiley \& Sons

XIV. Siedlecki, S. (2015) Relationship Between Nurses and Physicians Matter-American Nurses Association

XV. Styra R., Hawryluck L., Robinson S., Kasapinovic S., Fones C., Gold W.L. Impact on health care workers employed in high-risk areas during the Toronto SARS outbreak. J. Psychosom. Res. 2008;64:177183. [PMCfreearticle] [PubMed] [ $\underline{\text { Go }}$ ogle Scholar] [Ref list]

XVI. Sullivan, T. J. (1998). Collaboration: a health care imperative (pp. 646). New York: McGraw-Hill

XVII. Tam C.W.C., Pang E.P.F., Lam L.C.W., Chiu H.F.K. Severe acute respiratory syndrome (SARS) in Hong Kong in, 2003: stress and psychological impact among frontline healthcare workers. Psychol.

Med. 2004;34:1197-

1204. [PubMed] [Google

$\underline{\text { Scholar}}$ [Ref list]

XVIII. Workingnurse.com 